\title{
Tangibility in e-textile participatory service design with mental health participants
}

\author{
Sarah Kettley ${ }^{a *}$, Anna Sadkowska ${ }^{b}$, Rachel Lucas ${ }^{c}$ \\ ${ }^{a}$ Nottingham Trent University, UK \\ ${ }^{\mathrm{b}}$ Nottingham Trent University, UK \\ ${ }^{c}$ Nottingham Trent University, UK \\ *Corresponding author e-mail: sarah.kettley@ntu.ac.uk
}

\begin{abstract}
This paper introduces a project in which members of the Nottinghamshire Mind Network are engaged in the participatory design of e-textile service networks informed by the Person-Centred Approach mode of psychotherapy. Early reflections on separate e-textile and service design workshops reveal two distinct functions of tangibility in this process. First, we discuss how we have attempted to make novel technical futures tangible for participants through the experience of making textile circuits and soft handheld objects. Second, we discuss our finding that the experiences of participants in the mental health sector can lack presence for relevant audiences; our response to this, in the form of collaborative film work is introduced. The paper contributes to the technical and participatory design communities in its presentation of the Person-Centred attitude to the configuration of potentially vulnerable user groups, and the development of a methodology for the inclusive design of embedded technologies.
\end{abstract}

Keywords: configuration of users; person-centred approach; e-textiles; Internet of Things

\section{Introduction}

The authors are part of a large multidisciplinary research team, which includes textile designers, human-computer experts and psychotherapists. The project investigates the Person-Centred Approach of Carl Rogers as a methodology and framework for design, in some ways critiquing User-Centred and even Human-Centred approaches for their embodiment of unequal power relations (Kettley et al in press). The Person-Centred Approach is differentiated from other therapeutic modalities by its non-directive and nonexpert attitude. It is characterised by trust in the individual to grow and change (Wilkins, 2009:7), as well as the facilitative effect of therapeutic relationships (Rogers, 1957). The conditions Rogers identifies are empathic understanding (trying to put yourself in someone

This work is licensed under a Creative Commons Attribution-NonCommercial 4.0 International License. 
else's shoes), unconditional positive regard (warmth, valuing, prizing the other person and their experience), and congruence (being real, genuine, self-aware). In working with mental health, we view everyone as having mental health, experienced on a spectrum. We agree with Freeth (2007) that it is unhelpful and can be dehumanising to rely on a deficit model that prescribes diagnosis-treatment-cure as a response to distress and/or 'abnormal' experiences, processes or behaviours. Therefore we do not ask participants to disclose personal histories of mental health, and they are free to share any information - or not - as and when they choose. This is consistent with the principles that apply to the Mental Capacity Act (2005). In working with Mind service users there is an implication that participants have self-identified as experiencing mental health issues, and as such we ensure that at least one psychotherapist is present at workshops, along with Mind staff as appropriate, to provide support if required. This methodology is therefore differentiated from the standard intervention approach more normally found in technology application development, as it does not start with a population defined by a common medical condition. The contribution of the paper is to the debate on the configuration of users of technology, in this case, of e-textile interfaces in an Internet of Things.

The project is 18 months long, and includes three series of participatory workshops, intended as a whole to scaffold experiential learning around two near future concepts: electronic or 'e-textiles', and the Internet of Things. The first set of six workshops was held at Mind in Worksop, in the Midlands region in the UK. On average, six participants attended, although the actual number varied across sessions due to individuals' circumstances and wellness; this is a common characteristic of work in this field. The toolkit itself is intended as a convivial tool to facilitate both reflective and generative service design activities (Sanders and Stappers 2008), such as mapping personal journeys, identifying touchpoints, and developing stakeholder maps. The first two of these are most relevant at this stage of the project, based on discussions with staff at Mind, and drawing on the multidisciplinary workshop that framed the initial project proposal; in approaching emotional touchpoints it is important that we do not focus solely on negative stressors, but attempt to map the emotional management of the journey by each individual.

In between these sessions with mental health service users, we were invited to take our ideas to the Oakfield School and College in Nottingham, where we started to collaboratively develop one version of our participatory service design toolkit (figure 1). Oakfield is a large special needs school, attended by up to 160 children between the ages of 3 and 19 . The participants at our workshops included current students and members of the 'NICER' group, an advocacy group of alumni, staff and students, who have extensive experience of working on collaborative design projects with an $\mathrm{HCl}$ flavour. The second set of six workshops, which runs between November and December 2015, collaboratively tests the content, structure and delivery mode of a novel participatory loT service design toolkit. At the first session included two participants from the first e-textile sessions, although a third participant is expected to join sessions later on. Again, there were six participants. 
The next section discusses approaches to the human at the intersection of participatory design, technology and mental health through an account of two extant literature reviews, and our own emerging Person-Centred methodology. The paper then continues with a discussion on the project's attempts to make e-textiles as an emerging loT technology tangible (accessible) to the mental health co-researchers, and our attempts to make their experiences tangible for a range of disciplinary audiences through the design of the toolkit.

\section{Configuring users: participatory design research with mental health service users}

Mental health is considered "well represented" in the design literature review, based on a search of 11 databases from the viewpoint of a 'design outsider' (Chamberlain et al 2015, p. 11), "with 15 articles spanning mental health services, ... fear therapy, ... autism, ... and depression ..." (Chamberlain et al 2015, p.21). In addition, four articles were identified through the expert network, and six through the unpublished grey literature (p21). In this meta-review, autism was included, but dementia was not, in the definition of mental health. All of the four case studies focused on physical health (wheelchair design, visualisation of healthcare associated infections in clinical environments, the redesign of a resuscitation trolley, and a head support worn around the neck to improve posture and assist people with motor neuron disease. No mental health example was given (2015). Of the citations given as examples in the discussion of conditions (p21), one is concerned with social aspects of mental health (Carroll et al 2010), at least two deal with autism (Carroll et al 2010, Barakova 2011); and most are technology led, this being based on their being published in technology focused conferences and journals, and on the inclusion of such terms as 'robotics', 'webbased systems' and 'interactive systems' in the titles (Bae 2013, Bae and Heitkemper 2006, Sa et al 2012). Broader conditions like depression appear less frequently (Bae et al 2009). The second meta-review of the literature focuses on participatory approaches to the development of technology-based mental health and wellbeing interventions (Orlowski et al 2015). This review covers over 6000 citations, of which 17 studies were included in the systematic review, and focused on youth services. Of these, one reached the design proposal stage (Carroll et al 2010), and one was designed but not developed (Ekberg et al 2013).

In this review the authors identify four strands of Participatory Design (PD) in the literature: community based participatory research, participatory action research, participatory design, and user-centred design; of these, the first two appear to share core principles, and the reviewers see them as a single methodology, which strives to "develop an egalitarian partnership with a chosen community" (Orlowski et al 2015, p2). Participatory Design emphasises shared knowledge production and research outputs, while User-Centred Design remains led by an often implicit, but sometimes explicit, expert model (Sanders and Stappers 2008). 
This literature review made use of the term 'intervention', commonly found in more behavioural approaches to mental health. In contrast we suggest an attitude more in alignment with 'entanglement', a term used with citizen science and publics research to describe the bringing into awareness for people of contested issues (which can include imagined opportunities and issues with near future technologies) (cf Lindström and Ståhl 2014). Such bringing into awareness, we suggest, is a form of emerging tangibility or presence of the technology for users, which allows them to question and propose diverse futures. According to Sanders and Stapper's map, such an attitude may be found most readily in generative participatory practices of design-led research (2008).

\section{Making near future technologies tangible for mental health service users}

This part of the paper describes the generative co-design of two service design toolkit concepts. The evaluation of the toolkits is divided into reflections on the physical components of the kits, and on the larger contexts of their creation and use. Critical incidents, both negative and positive notable moments, are used to illustrate the impact of some of the formal aspects of the kits on the experiences of individuals. Critical incidents are a useful way to organise reflection on practice and action-oriented heuristic research (Moon 2013).

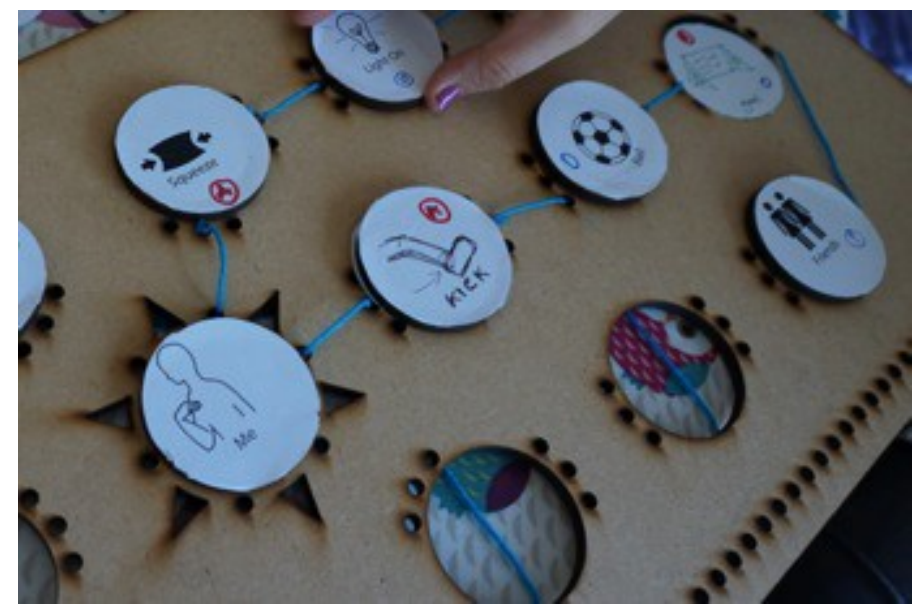

Figure 1 Intitial concept for a service design tool, collaboratively developed at Oakfield School.

The first concept for the service design toolkit comprised a laser cut wooden board with disc counters that could be slotted into holes to create a story (figure 1). Discs had images of objects, actions, and outputs/effects on them and these were discussed and extended collaboratively with the Oakfield School participants. Strings could be used to connect different elements of these stories. The second concept for the toolkit is based on serious play and the use of Lego in service design (Lab for Living 2014) (figure 2). It comprises a range of figures (human and animal), things found on walking through a town (trees, traffic lights, cars, roads etc), and boxes to represent buildings; small wooden bird houses are used 
to represent Mind. The elements of this kit have been somewhat creatively sourced due to time restrictions, and as a 'kit' there is a lack of visual coherence; as designers the urge is to rectify this, imposing an acceptable aesthetic according to our own professions. However, it may be that offering a range of options will allow individual responses to emerge in keeping with the person-centred ethos of the project. What is left for individuals to personalise with stickers, paint etc, and what is presented as choice through different forms of similar elements, is something we continue to work in as we try to optimise the kits for future use.
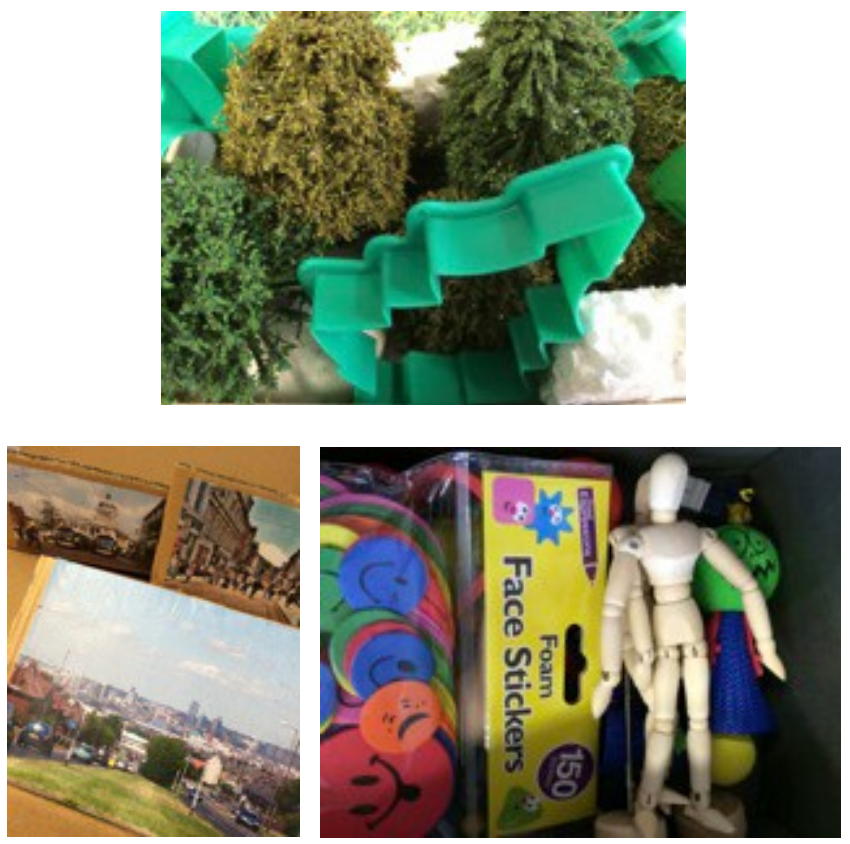

Figure 2 Trees, place cards and figures in the service design toolkit developed with adult mental health service users at Mind.

In both contexts (special needs at Oakfield, and adult mental health at Mind), pairs and triads formed quickly around the artefacts of the service design toolkit; they became props (Sanders et al 2010) available to spontaneous individual systems of meaning making, dynamically signifying a range of actions, objects and experiences. In one incident with a female participant at Mind, a slow start with the tools seemed due to a lack of exact counterparts for what she wanted to recall about her journey that day; images and characters were different scales and seemed to take on different levels of importance; some of the character pieces had strange, exaggerated facial expressions that the researcher (the first author in this case) found difficult - she had to consciously bracket her own negative feelings to allow the participant to work with whatever became useful to her in creating her own narrative; however, after a short time, the participant shifted from looking for literal representations to using what was available in a more metaphorical way. She accomplished this in conversation with the first author, so the meaning of these artefacts was shared they communicated effectively the 40-minute walk she makes twice a week to get to Mind from her apartment. The relationship between the researchers/facilitators and the participants is therefore crucial to support in the design of the toolkit. Multiples of common 
artefacts are needed so that small teams can work effectively and safely without the need to negotiate shared use of popular items, which for this group can be potentially stressful.

In the first week of the service design workshop at Mind, two of the participants also chose to leave after a short time, aware of their own stress levels in a busy room with new people. While participants in this sector will almost certainly be dealing with unknown external factors that affect their experience, there are certain aspects of the toolkit and its context of use that may contribute to incidents such as this. IDEO point out the need to consider room layout so that people have the space to move around freely, access resources and refreshments, and use the wall and table spaces creatively (2016). At Mind, we had use of a communal space with a small kitchen area at one end, which the participants were familiar with from other drop-in activities. In working with e-textiles in the first phase of the project, we had already found the space quite constrained, as the ratio of participants to facilitators was almost 1:1. In this second Service Design phase, the physical scale and materiality of the toolkit components had a negative impact on participant experience. The cardboard boxes holding the various props took up valuable space, and some individuals even found the sound of them in that space disconcerting. Participants found it hard to reach what they needed, or to see what was available to them. In addition, there is an implicit expectation in these toolkits that people will be able to work in small groups of 4 or 5 , rather than the safer pairings that had developed in phase one. To work confidently with other people is a significant achievement for many mental health service users and should be seen as a potential outcome rather than a starting point for service design activity in this sector.

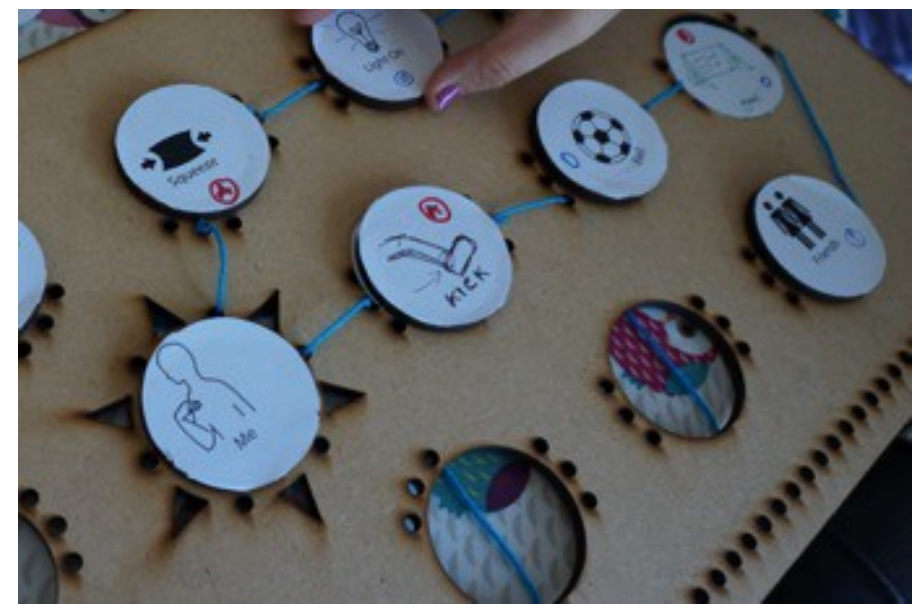

Figure 1 Intitial concept for a service design tool, collaboratively developed at Oakfield School.

\section{Pragmatic findings and flights of fancy in person-centred research}

The personal accounts of journeys taken to Mind have varied. In some cases, the route has both negative and positive touchpoints, and these can depend on the time of year and the time of day (eg school finishing time); they are approached pragmatically by the individual, who knows what to expect and who is therefore able to cope emotionally: "that's me feeling frustrated [laughing]" (figure 3). Others are routes that have been to some extent 
engineered as alternatives to more stressful ones involving previous traumatic incidents: "I would never ever go that way".

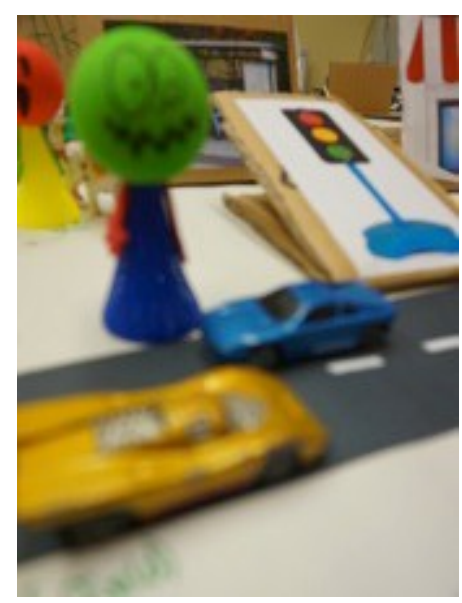

Figure 3 Elaine's frustrated figure at a busy crossing.

On the other hand, 'flights of fancy' are an acceptable component of participation in the Person-Centred research framework (Wilkins 2010), and they were noticeable in interactions where individuals felt comfortable with each other. Where the toolkit was used to imagine future scenarios at Oakfield, responses included the fantastical as well as the familiar: "I want to fly in a hot air balloon".

As researchers we may also find such fantastical comments occurring with other participant populations; it has been suggested that imagining near-future technologically enabled scenarios in ones own life is sometimes more challenging than taking on the role of designer and transposing to someone else's (with apparently more easily identified 'needs'). 'Fanciful' was one of four notional lifeworlds identified in an analysis of a female friendship group's responses to a novel suite of networked digital jewellery, along with 'immediate scenarios', 'own lifeworld' and 'other people's worlds' (Kettley and Smyth 2006). As in that project, individuals here mixed the everyday or 'own lifeworld' with the fanciful in imagining uses and experiences: "is breakfast ready for you when you come downstairs?" Where participants in the Internet of Soft Things workshops have indicated possible uses for other people's lifeworlds, those people have often been sitting right beside them, and there is an established supportive relationship (figure 4). When figuring future things for their own lifeworlds, participants tended to include details about which music should play as output, or what form and colour the object should assume; in contrast, when imagining premises for use for others, helpful and assistive functions have been emphasised. Carers started to talk about the range of different response teams who could be involved under different circumstances, although this will need a further workshop to develop fully. In some cases, then, it is important when opening up the options for individuals that we do not then try to 'boil down' their responses to a generalisable outcome - E's premises for her own use developed when she wore a sweater with tassels, and she began to relate very specific textile qualities to the possible forms for an e-textile interface for her own lifeworld. In this 
case, the tangibility of the prop available to the participant directly informed their understanding of opportunities with the future technology.
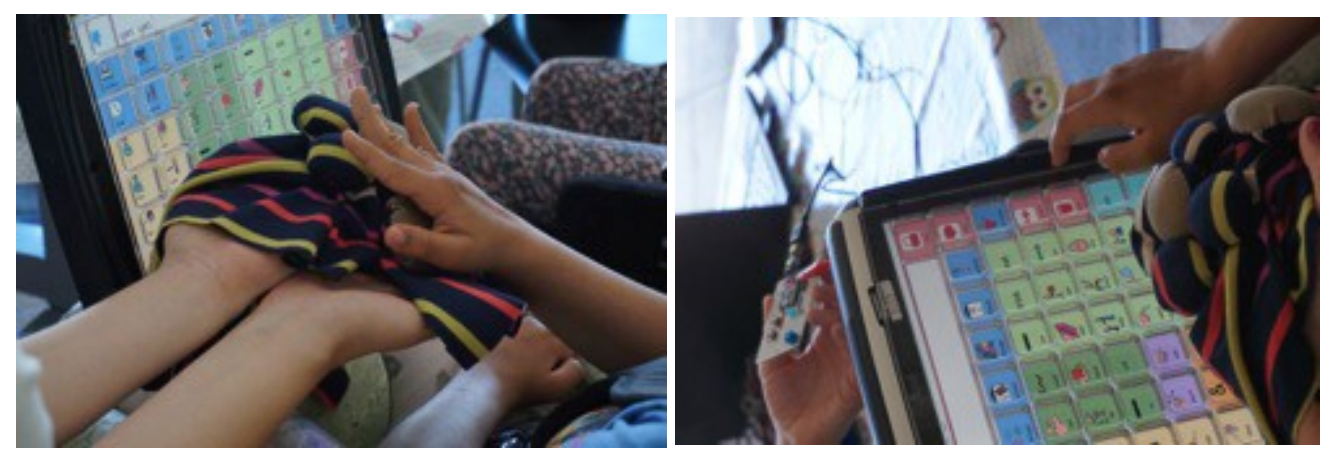

Figure 4 E and $C$.

With reference to this point, much of the feedback from both the e-textile and service design workshops has been concerned with the experience of creative entanglement being as important as the designed outcome; it may be that for some markets and users, the cocreation of the convivial design tools is as important as the participatory design of the final service and product concepts.

We found that participants at Oakfield were generally happy to use what was given in the toolkit, while at Mind, the feedback concerned the need for completely blank cards, which could become any type of item as needed. At Oakfield, the e- textiles were included as elements in the kit (figure 5); at Mind, the new group of participants has been reintroduced (or introduced for the first time) to the concept of e- textiles, in addition to working through their journey narratives with the service design kit. 


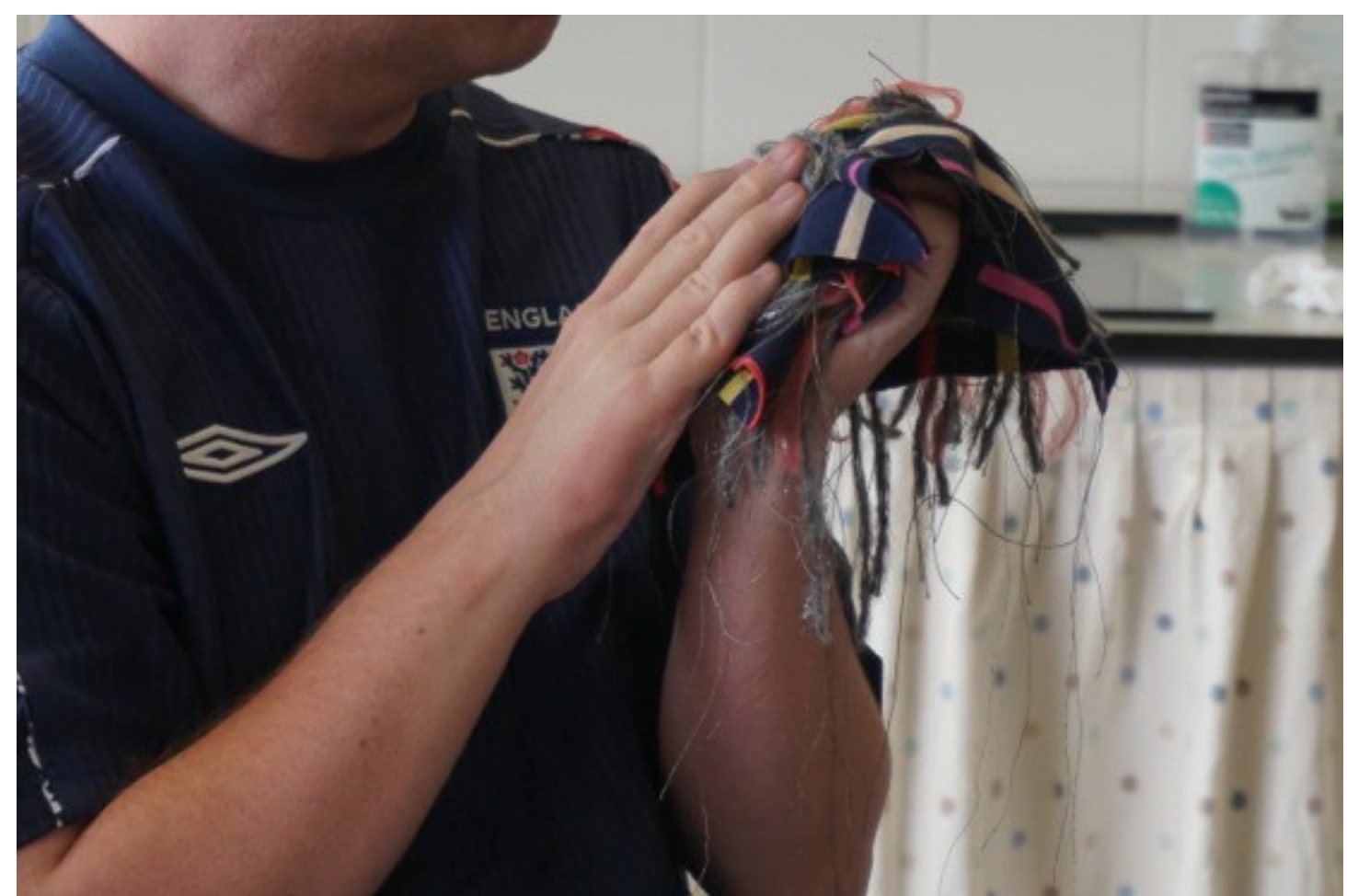

Figure 5 e-textiles at Oakfield; a soft switch made by the researchers and taken to the school as creative props.

The next set of workshops will attempt to integrate these experientially. Walks designed as part of the forthcoming workshops are intended to support further discussion on the networks of soft things as part of individuals' own lifeworlds, and approach the ambitions of research 'in-the-wild' (difficult otherwise with mental health service users).

While our interest in the nature of tangibility of the e-textiles and service design toolkit, and the subsequent availability of these near-future technologies to participants' own lifeworld imaginaries continues, another aspect of tangibility is emerging from working with mental health service users. The next section reflects on the project's concerns with the representation of participants' experiences and our making of them available to wider research audiences as 'evidence'.

\section{Making the person tangible in design research with mental health}

As part of the participatory design approach, we collected audio-visual data of workshops in which the two communities learnt about e-textiles and the technosocial imaginary of the Internet of Things (IOT). The aim of these workshops was to open up the social imaginary to allow active participation in it. We soon noticed in transcribing the sessions with mental health service users, that the individual was often obscured or even absent, although we had personal experience of interacting with them in the workshops, and indeed with their full 'presence' in the moment. This was more so for the mental health participants than the 
special needs participants, suggesting that while it is a received wisdom that mental health issues may be physically 'invisible', they may also remain invisible in standard research processes, in which speech and text are paramount. In response, we decided to add an extra session to the six weeks in the first e-textile phase of the project at Mind, in which participants would have the opportunity to reflect together, or with their now familiar research facilitators, on the experiences of having taken part. We also prepared to make individual video interviews, and three participants agreed to take part in this process. These participants gave permission for their first names to be used in relation to their films, so we also refer to them here by their real names: Chris, Elaine and Meg. The final moving image outcome can be seen hosted online by participatory arts charity, Salamanda Tandem (Jones and Fielding 2015). The film was developed by Isabel Jones, creative director of Salamanda Tandem, who has 25 years of experience in developing person-centred approaches to cocreativity and film-making. Levels of consent for the film were discussed with participants so that informed consent became personalised: 'you can video and/or audio record me' or 'you can show still images of my hands/face/whole body' or 'you can show my words as text'. These decisions were respected, and we did not seek to influence them, even if this had a significant impact on the content of the film. We set aside our artistic preferences and personal agendas, in order to maintain trust and empathic understanding of the participants. Of three people who took part:

- One agreed to audio and visual recording of whole body

- One agreed to audio and visual recording of hands

- One agreed to visual recording and still images of hands and for words to be used as text

At the recording we tried to create a supportive environment, by filming in the same geographical location as the workshops, although in a smaller, more cosy room upstairs, and with facilitators and Mind staff present to offer prompts and support where necessary. The initial film, photography and audio recording sessions, took approx.1 hr $15 \mathrm{mins}$ for each participant. Key to the approach in these sessions was in restraining the outcome driven processes often seen in the process of filmmaking. The use of story boarding, pre-laid down narrative structures, exact durations of the work, or even the media used were all put on one side in favour of a more participant-centred approach. For example, in one session the role of auteur / director shifts as the sound technology is handed over, which frees up one participant to use her own empathic and reflective skills to work as interviewer and sound recordist herself. In this way, and even in the flexible media used, the gathering of photographs, film clips, hand written evaluations, and audio recordings, the process becomes an extension of our co-design research, rather than purely as a post hoc evaluation of it.

The final film 'An Internet of Soft Things: a dialogue in co-design with Mind' duration 20 min 16 secs, (Jones and Fielding 2015) has been constructed in such a way that it might be later de-constructed into component parts and re-constructed for different audiences. 
Showing this film at various dissemination events has been salutary. There are moments that make the researcher-presenters smile in recollection, while the audience sit confused: the shot of Chris' cigarette packet in a top pocket is one of these moments, which demonstrates the limitations of the medium to communicate how significant Chris' engagement was during the workshops. Instead of leaving up to ten times in three hours, he would typically leave once, to have a cigarette break; according both to himself, and to the staff at Mind, this was an exceptional achievement for him in managing his anxiety levels in large groups. In addition, we have found it necessary to prepare the audience before showing the films; as discussed, these have not been made with our own artistic practice in mind; on the day, individuals may be speaking indistinctly because of new medication; some are almost non-verbal, and others construct narratives in what might seem to be problematic ways because their memory has been affected by their condition. All of these we seek to preserve as far as possible, instead of editing out.

\section{Future work}

The second phase of workshops will complete in December 2015, with a further Future Workshop (Jungk and Müllert 1987) phase planned for January 2016, in which participants will apply their recent experience to the conceptual design of a new venue for mental health services in either Worksop (for the Bassetlaw district), or in central Nottingham, where the charity does not currently have a site. The ambition is to include policy makers and procurement processes in mental health at the local level, thereby extending the notion of entanglement and developing the concept of the participative process in mental health research ('PPI') from a design perspective. The tangibility of the service design toolkit will be further explored to explore how this supports or precludes positive aspects of tangibility for participants with lived experience of mental health issues. We will continue to make films with our participants where possible, and to reflect on how this is done in an ethical way, while having the desired impact on the audiences needed for research to have its intended impact at practice and policy levels.

Acknowledgements: We gratefully acknowledge the contribution made by the NICER group at Oakfield School, and all the participants at Worksop Mind. The project has been funded by an EPSRC Research-in-the-Wild grant: EP/L023601/1.

\section{References}

Bae, J. (2013) Development and application of a web-based expert system using artificial intelligence for management of mental health by Korean emigrants, Journal of Korean Academy of Nursing, 43(2), pp 203-14.

Bae, J., Wolpin, S., Kim, E., Lee, S., Yoon, S. \& An, K. (2009) Development of a user-centered health information service system for depressive symptom management, Nursing and Health Sciences, 11(2), pp 185-93.

Bae, J. and Heitkemper, M. (2006) Development of a web-based health information service system for maternal health care, Studies in Health Technologies and Informatics 122, pp 963-4. 
Barakova, E.I. (2011) Robots for social training of autistic children: empowering the therapists in intensive training programs, Proceedings of the World Congress on Information and Communication Technologies (WICT 2011), 11-14 December 2011, Mumbai, India, pp 14-19. Piscataway: IEEE Service Center.

Bidean (2015). Kite-Ballet. Art, Design and New Technology for Health: The Sackler Conference 2015, http://bideanuk.wix.com/bidean\#!projects/c17b1, (Accessed 20 November 2015).

Carroll, J., Burge, J., Robertson, S., \& Rosson, M. (2010) Participatory design of an autism community network to enhance community participation, health, and well-being, Proceedings of The ACM International Conference On Health Informatics - IHI' 10 .

Chamberlain, P., Wolstenholme, D. \& Dexter, M. (2015) The state of the art of design theory and practice in health: an expert-led review of the extent of the art and design theory and practice in health and social care, Project Report. Sheffield: Sheffield Hallam Univeristy.

Ekberg, J. Timpka, T., Angbratt, M., Frank, L., Norén, A., Hedin, L., Andersen, E., Gursky, E. A. \& Andersson Gäre, B. (2013) Design of an online health-promoting community: negotiating user community needs with public health goals and service capabilities, BMC Health Services Research 2013, 13, pp 258.

Freeth. R. (2007) Humanising Psychiatry and Mental Health: The Challenge of the Person-Centred Approach, Oxford: Radcliffe.

Gilburt, H. (2015) The worrying truth about mental health services, The Kings Fund, http://www.kingsfund.org.uk/publications/articles/worrying-truth-about-mental-health-services, (Accessed 20th November 2015).

IDEO (2016) Design Kit: The facilitator's Guide, http://www.designkit.org/, (Accessed 3 February 2016).

Jones. I. and Fielding. G. (2015) 'An Internet of Soft Things; a dialogue in co-design with Mind', Salamanda Tandem UTube https://youtu.be/YixEuzlOWfc, (Accessed 23 March 2016).

Jungk, R. and Müllert, N. (1987) Future workshops: How to Create Desirable Futures, London, England, Institute for Social Inventions.

Kettley, S., Kettley, R. and Lucas, R. (IN PRESS) Towards a Person-Centred Approach to Design for Personalisation, in Fisher, T. and Kuksa, I. (eds.), Design for Personalisation, Gower.

Kettley, S., and Smyth, M. (2006) Plotting Affect and Premises for Use in Aesthetic Interaction Design: towards evaluation for the everyday, Proceedings of the HCIO6 Conference on People and Computers $X X$, Springer Verlag, pp 17-22.

Kettley, R., Lucas, R., Jones, I. \& Kettley, S. (2015) Practice-led Critical Reflection on the Ethics of 'An Internet of Soft Things', Proceedings of the 8th International Conference on Interactive Technologies and Games, Nottingham, 22-23 October 2015. Los Alamitos, CA: IEEE Computer Society.

Lab for Living. (2014) Creative Practices in Knowledge Mobilisation, http://www.lab4living.org.uk/creative-practices-in-knowledge-mobilisation-2, (Accessed 20 November 2015).

Lindström, K and Ståhl, Å. (2014) Publics-in-the-Making: Crafting Issues in a Mobile Sewing Circle, in

Ehn, P., Nilsson, E. M. and Topgaard, R. (eds.), (2014). Making Futures: Marginal notes on innovation, design and democracy, Cambridge, CA: MIT Press, pp 303-322.

Mental Capacity Act (2005) http://www.legislation.gov.uk/ukpga/2005/9/contents, (Accessed 15 June 2015).

Moon, J. (2004) A Handbook of Reflective and Experiential Learning: Theory and Practice, Abingdon: Routledge. 
Orlowski, S. K., Lawn, S., Venning, A., Winsall, M., Jones, G. M., Wyld, K., Damarell, R. Aa, Antezana, G., Schrader, G., Smith, D., Collin, P. and Bidargaddi, N. (2015) Participatory Research as One Piece of the Puzzle: A Systematic Review of Consumer Involvement in Design of Technology-Based Youth Mental Health and Well-Being Interventions, JMIR Human Factors, 2 (2).

Rogers, C.R. (1957) The Necessary and Sufficient Conditions of Therapeutic Personality Change, in Kirschenbaum, H. and Henderson, V.L. (1990) The Carl Rogers Reader, London: Constable, pp 219235.

de Sá, M., and Carriço, L. (2012) Fear therapy for children, Proceedings Of The 4th ACM SIGCHI Symposium On Engineering Interactive Computing Systems - EICS '12. New York, New York: ACM Press, pp 237.

Sanders, E. and Stappers, P. (2008) Co-creation and the New Landscapes of Design, Co-design 4 (1), pp 5-18.

Sanders, E., Brandt, E., and Binder, T. (2010) A Framework for Organizing the Tools and Techniques of Participatory Design, Proceedings of the $11^{\text {th }}$ Biennial Participatory Design Conference, 3 December 2010, Sydney, Australia: ACM Press.

Wilkins, P. (2009) Person-Centred Therapy: 100 Key Points, Hove: Routledge.

Wilkins, P. (2010) Researching in a Person-Centred Way, in Cooper, M., Watson, J. and Holldampf, D. (eds.), Person-Centred and Experiential Therapies Work, Ross-on-Wye: PCCS Books, pp 215-239.

About the Authors:

Sarah Kettley is Reader in Relational Design at Nottingham Trent University.

Anna Sadkowska recently completed her PhD, and is a Research Assistant on the Internet of Soft Things project.

Rachel Lucas is a Research Fellow on the Internet of Soft Things project, and a practising psychotherapist. 